\title{
A CROSS-SECTIONAL STUDY OF GENDER DIFFERENCES IN ATTEMPTED SUICIDE
}

\author{
Chilasagaram Shanthi', Rasamsetti Vijaya Kranthi ${ }^{2}$
}

1Associate Professor, Department of Psychiatry, Government Medical College, Nizamabad, Telangana, India. ${ }^{2}$ Associate Professor, Department of Psychiatry, Institute of Mental Health, Osmania Medical College, Hyderabad, Telangana, India.

ABSTRACT
BACKGROUND
Suicides are more common among suicide attempters. Most of the suicide attempts were done
The gender is the most powerful predictor of suicide attempts in the form of type of mental
lethality of attempt.
Aim- The study was undertaken to evaluate the gender related differences in attempted suicide.

\section{MATERIALS AND METHODS}

A cross-sectional study was conducted in Psychiatry Department, Mamatha General Hospital, Khammam. Sample consisting of 100 subjects with attempted suicide were assessed on socio-demographic and suicide attempt data and MINI Plus. The diagnosis was confirmed by International Classification of Diseases, Tenth Revision (ICD-10). Data was tabulated and analysed using Statistical Package for the Social Sciences Version 13 (SPSS-13).

\section{RESULTS}

Out of 100 suicide attempters, 35 were males and 65 were females. Most of the females with psychiatric disorder attempted suicide (62.5\%) compared to males (37.5\%). Female suicide attempters were more with Depression (29\% in female, $24.24 \%$ in male) and Schizophrenia (18.18\% in female, $12.12 \%$ in male). Male suicide attempters were more with Alcohol Dependence Syndrome (18.18\% in male, $3.63 \%$ in female). $62 \%$ of total subjects impulsively attempted suicide compared to planned only (38\%). In these, majority were males $77.14 \%$ followed by females $(53.84 \%)$. This difference was statistically significant ( $<<0.05)$. Out of total, $9 \%$ were intoxicated and all of them i.e. $25.7 \%$ were males. Lowest among females (0\%) and most of the females were with clear consciousness and the males were intoxicated during the time of Attempt $(100 \%)$. This difference was statistically significant $(\mathrm{p}<0.05)$.

\section{CONCLUSION}

Psychiatric disorder was found in $88 \%$ of suicide attempters. Most of the females with psychiatric disorder attempted suicide compared to males. Depressive disorders, schizophrenia and schizoaffective disorders are more in female attempters and alcohol dependence syndrome in male attempters. Impulsive attempts, intoxicated with alcohol during the attempt and used lethal methods were significantly more common in males. Household chemicals are used mostly by females. The number of first and repeated attempts difference is minute with gender.

\section{KEY WORDS}

Suicide, Attempted Suicide, Gender Differences.

HOW TO CITE THIS ARTICLE: Shanthi C, Kranthi RV. A cross-sectional study of gender differences in attempted suicide. J. Evolution Med. Dent. Sci. 2018;7(44):4703-4708, DOI: 10.14260/jemds/2018/1050

\section{BACKGROUND}

The word 'Suicide' is derived from the Latin word for "SelfMurder." It is a fatal act that represents the persons who wish to die. Nearly 800,000 people die due to suicide every year, which is one person every 40 seconds, making it the $18^{\text {th }}$ leading cause of death in 2016 globally. Out of these 135,000 (17\%) are residents of India (Suicide in India, 2014). ${ }^{1}$ In 1987 and 2007, the suicide rate increased from 7.9 to 10.3 per 100,000 studied by Vijaya Kumar L et al (2007). ${ }^{2}$

A suicide attempt is a clear indication that something is gravely wrong in a person's life. The most common

'Financial or Other Competing Interest': None.

Submission 01-10-2018, Peer Review 00-09-2018,

Acceptance 16-10-2018, Published 29-10-2018.

Corresponding Author:

Dr. Rasamsetti Vijaya Kranthi,

D. No. 8-3-167/A/65, First Floor,

Lane Opp. Municipal Water Tank,

Vikaspuri Colony, Lane Opp. ESI Hospital,

Erragadda, Hyderabad-500038, Telangana, India

E-mail:dr.vijayakranthi@gmail.com

DOI: $10.14260 /$ jemds/2018/1050

\section{(c) (i) $(9)$}

underlying disorder is depression, $30 \%$ to $70 \%$ of suicide victims suffer from major depression or bipolar (manicdepressive) disorder by Strom $P$ et al (2014). ${ }^{3}$

There are indications that for each adult who died of suicide, there may have been more than 20 others attempting suicide (WHO 2016). Those who commit suicide upto $40 \%$ would have attempted before as reported by Maris RW et al (1992). ${ }^{4}$

The term "attempted suicide" encompasses a variety of self-destructive behaviours, ranging from serious lifethreatening acts to relatively minor gestures primarily aimed at attracting attention. Suicide attempts would fall between suicidal ideation and completed suicide. Literature makes a distinction between those who 'attempt' and those who 'complete' suicide. In that those who attempt are more likely to be females, under 35 years of age, use low means of lethality (e.g. wrist laceration), do it in a setting where there are high chances of rescue and usually suffer from adjustment disorder or personality disorder. In comparison to those who complete suicide are usually males, over 60 years of age, use high means of lethality (e.g. firearms, hanging), do it in a 
setting where there are low chances of rescue and usually suffer from mood disorder and substance abuse.

According to WHO estimates for the year 2020, approximately 1.53 million people will die from suicide and 10 to 20 times more people will attempt suicide worldwide. These estimates represent on average one death every 20 seconds and one attempt every one to two seconds. Although of low predictive value, the presence of psychopathology is probably the single most important predictor of suicide. Accordingly, approximately 90 percent of suicide cases meet the criteria for a psychiatric disorder, particularly major depression, substance use disorders, cluster B personality disorders and schizophrenia by Gvion Y et al (2012). ${ }^{5}$

Gender is one of the important socio-demographic factors that have been shown as a determinant of suicidal behaviour by Zhang J et al (2005), ${ }^{6}$ Qin P et al (2000) 7 and Hawton K et al (2000). ${ }^{8}$

Haw C et al (2003), ${ }^{9}$ Nordentoft $M$ et al (2008), ${ }^{10}$ Pompili $M$ et al (2009) ${ }^{11}$ and Canetto SS et al (1997) ${ }^{12}$ noticed suicidal behaviour differs between genders as males appear to harbour a higher intent to die and consequently use more violent and lethal means, while women seemingly attempt for motives other than death.

The effect of most risk factors differs significantly by gender observed by Ping Qin et al 2003.13 According to Isometsä et al (1998),14 most males and a substantial proportion of female suicides die in their first suicide attempt. A fact that necessitates early recognition of suicide risk, particularly among males. Recognition of periods of high suicide risk on the grounds of recent non-fatal suicide attempts is likely to be important for suicide prevention among females. Successful suicide prevention calls for sensitive understanding of suicidal intent and early intervention.

Sudhir Kumar CT et al (2006) ${ }^{15}$ said "studying this highrisk group has significant preventive implications and identification of gender differences may play a notable role in this regard."

These findings emphasise the importance of adequate management of suicide attempters and suggesting that it would be a useful approach to try to prevent completed suicide. Analogous to the traditional public health concepts of primary, secondary and tertiary prevention has been rightly pointed out by Katsching et al (1980)16 that one can speak of actions taken before attempted suicide as "prevention," during treatment of attempted suicide as "intervention" and after this as "postvention." In the above background, the present study has been undertaken to know the intention of deeper insight into the mental health and gender related differences in suicide attempters.

\section{Aims}

The study was to undertake to evaluate the gender related differences in attempted suicide.

\section{MATERIALS AND METHODS}

This is a cross-sectional study which was conducted in Department of Psychiatry, Mamata General Hospital, which is a tertiary care hospital. Study sample of 100 subjects who attempted suicide was collected during the study period of one year. A case of suicide attempt defined by Srivastava et al (2004)17 - "A person who had made deliberate act of self- harm consciously aimed at self-destruction, irrespective of his or intention to die, with non-fatal outcome." Due to accompanying need for immediate medical attention and the medico-legal nature of the cases, almost all cases of attempted suicides were admitted in casualty. Once patient becomes stable, informed consent was obtained with assuring confidentiality followed by psychiatric interview was taken with proforma having the socio-demographic data and also given a proforma to document suicide attempt data related to gender in the form of nature of suicide attempt, termination behaviour at the time of suicide attempt, method of suicide attempt, lethality of suicide attempt, number of suicide attempts and help sought before attempt or not along with this administered Mini International Neuropsychiatric Interview Plus (MINI Plus) by Sheehan DV et al (1998), ${ }^{18}$ is a short structured diagnostic interview, developed jointly by psychiatrists and clinicians for DSM IV and ICD-10 based psychiatric disorders. MINI Plus were designed for clinical practice and research in psychiatric primary care setting and takes less time to administer when compared to other similar structured interviews.

Diagnosis was given according to International Classification of Diseases, Tenth revision ICD-10, WHO; (1992). ${ }^{19}$ The data was tabulated and analysed. The findings have been discussed. Along with all subjects, a supportive psychotherapeutic relationship was maintained till they got discharged.

\section{Inclusion Criteria}

1. Age is between 18 and 85 years.

2. Both genders were included in the study.

3. Those patients who have attempted suicide.

4. Should be physically fit to answer the questions with a reliable informant.

\section{Exclusion Criteria}

1. Not giving consent for the study.

2. Who are not cooperative and having cognitive deficits.

\section{Statistical Analysis}

Data entry was done in Excel and the data was analysed using Statistical Package for the Social Sciences Version 13 (SPSS13). Demographic descriptive analysis was done for the sample. Intragroup data are described as means and percentages. Data are represented by using pie chart and histogram. Chi-square tests are used to test significance. Statistical significance was set at 0.05 .

\section{RESULTS}

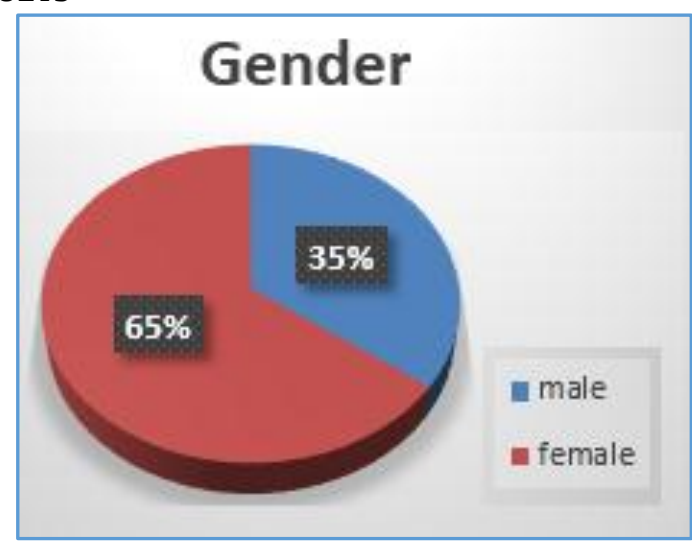

Graph 1. Depicting distribution of Male and Female Suicide Attempters 


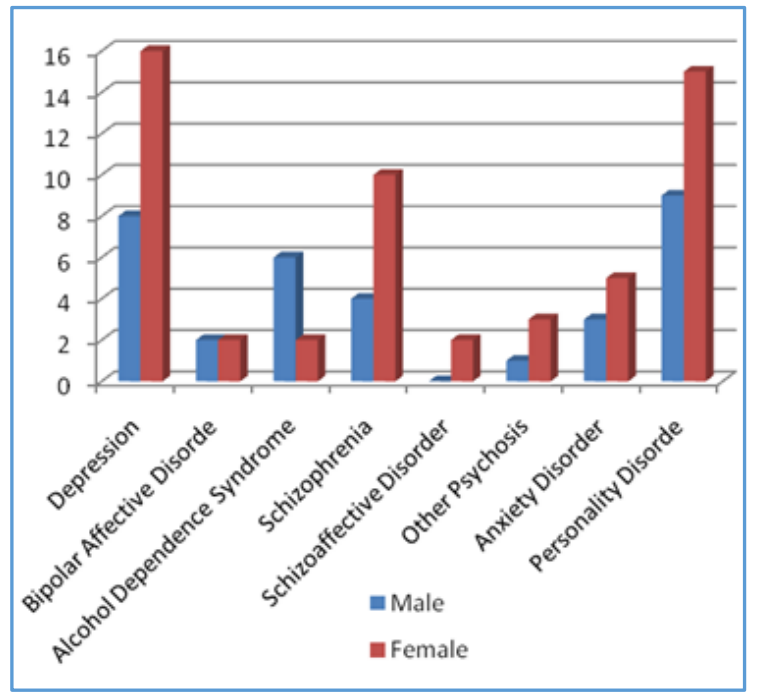

Graph 2. Relationship between

Psychiatric diagnosis and Gender

\begin{tabular}{|c|c|c|c|}
$\begin{array}{c}\text { Nature of } \\
\text { Suicide Attempt }\end{array}$ & Male & Female & Total \\
\hline Planned & $8(22.85 \%)$ & $30(46.15 \%)$ & $38(38 \%)$ \\
\hline Impulsive & $27(77.14 \%)$ & $35(53.84 \%)$ & $62(62 \%)$ \\
\hline Total & $\mathbf{3 5 ( 1 0 0 \% )}$ & $\mathbf{6 5 ( 1 0 0 \% )}$ & $\mathbf{1 0 0 ( 1 0 0 \% )}$ \\
\hline Table 1. Depicting Relationship between Nature of Suicide \\
Attempt and Gender \\
\hline P < 0.05, Significant.
\end{tabular}

$\mathrm{P}<0.05$, Significant.

\begin{tabular}{|c|c|c|c|}
\hline $\begin{array}{c}\text { Termination } \\
\text { Behaviour }\end{array}$ & Male & Female & Total \\
\hline Intoxicated & $9(25.71 \%)$ & $0(0 \%)$ & $9(9 \%)$ \\
\hline $\begin{array}{c}\text { Clear } \\
\text { Consciousness }\end{array}$ & $26(74.28 \%)$ & $65(100 \%)$ & $91(91 \%)$ \\
\hline Total & $\mathbf{3 5 ( 1 0 0 \% )}$ & $\mathbf{6 5 ( 1 0 0 \% )}$ & $\mathbf{1 0 0 ( 1 0 0 \% )}$ \\
\hline
\end{tabular}

Table 2. Relationship between Termination Behaviour and Gender

$\mathrm{P}<0.05$, Significant.

\begin{tabular}{|c|c|c|c|}
\hline Method of Attempt & Male & Female & Total \\
\hline Pesticide & $\begin{array}{c}18 \\
(51.42 \%)\end{array}$ & $31(47.69 \%)$ & $49(49 \%)$ \\
\hline Burning & $3(8.57 \%)$ & $2(3.07 \%)$ & $5(5 \%)$ \\
\hline $\begin{array}{c}\text { Household } \\
\text { chemicals }\end{array}$ & $0(0 \%)$ & $9(1.38 \%)$ & $9(9 \%)$ \\
\hline Hanging & $3(8.57 \%)$ & $7(10.76 \%)$ & $10(10 \%)$ \\
\hline Self-Injury & $1(2.57 \%)$ & $3(4.61 \%)$ & $4(4 \%)$ \\
\hline Others & $\begin{array}{c}10 \\
(28.57 \%)\end{array}$ & $13(20 \%)$ & $23(23 \%)$ \\
\hline Total & $\begin{array}{c}\mathbf{3 5} \\
(\mathbf{1 0 0} \%)\end{array}$ & $\mathbf{6 5 ( 1 0 0 \% )}$ & $\mathbf{1 0 0 ( 1 0 0 \% )}$ \\
\hline
\end{tabular}

Table 3. Relationship between Method of Suicide Attempt and Gender

$\mathrm{P}>0.05, \mathrm{NS}, \mathrm{df}=1$

\begin{tabular}{|c|c|c|c|}
\hline Lethality & Male & Female & Total \\
\hline Lethal & $\begin{array}{c}15 \\
(42.85 \%)\end{array}$ & $26(40 \%)$ & $41(41 \%)$ \\
\hline $\begin{array}{c}\text { May or may not be } \\
\text { lethal }\end{array}$ & $\begin{array}{c}20 \\
(57.14 \%)\end{array}$ & $39(60 \%)$ & $59(59 \%)$ \\
\hline Total & $\mathbf{3 5 ( 1 0 0 \% )}$ & $\mathbf{6 5 ( 1 0 0 \% )}$ & $\mathbf{1 0 0}(\mathbf{1 0 0} \%)$ \\
\hline Table 4. Relationship between Lethality of Suicide Attempt \\
and Gender
\end{tabular}

$\mathrm{P}>0.05$, NS.

\begin{tabular}{|c|c|c|c|}
\hline $\begin{array}{c}\text { No. of } \\
\text { Attempts }\end{array}$ & Male & Female & Total \\
\hline First & $26(74.28 \%)$ & $49(75.38 \%)$ & $75(75 \%)$ \\
\hline Repeated & $9(25.71 \%)$ & $16(24.62 \%)$ & $25(25 \%)$ \\
\hline Total & $\mathbf{3 5 ( 1 0 0 \% )}$ & $\mathbf{6 5}(\mathbf{1 0 0 \% )}$ & $\begin{array}{c}\mathbf{1 0 0} \\
\mathbf{1 0 0 \%}\end{array}$ \\
\hline
\end{tabular}

Table 5. Relationship between No. of Suicide Attempts and Gender

$\mathrm{P}>0.05$, NS.

\begin{tabular}{|c|c|c|c|}
\hline $\begin{array}{c}\text { Help Sought } \\
\text { before Attempt }\end{array}$ & Male & Female & Total \\
\hline Psychiatric & $5(14.2 \%)$ & $8(12.30 \%)$ & $13(13 \%)$ \\
\hline Non-help seekers & $\begin{array}{c}29 \\
(82.85 \%)\end{array}$ & $53(81.53 \%)$ & $82(82 \%)$ \\
\hline General practitioner & $1(2.85 \%)$ & $4(6.15 \%)$ & $5(5 \%)$ \\
\hline Total & $\begin{array}{c}\mathbf{3 5} \\
(\mathbf{1 0 0} \%)\end{array}$ & $\mathbf{6 5 ( 1 0 0 \% )}$ & $\mathbf{1 0 0 ( 1 0 0 \% )}$ \\
\hline
\end{tabular}

Table 6. Relationship between Help sought before Suicide Attempt and Gender

$\mathrm{P}>0.05, \mathrm{NS}, \mathrm{df}=1$, Non-help seekers vs. others.

\section{DISCUSSION}

The aim of the study is to know the gender differences related to suicide attempts. Out of 100 suicide attempters, 35 were males and 65 were females. $88 \%$ of suicide attempters were suffering with mental disorder, while $12 \%$ were not. Showing mental disorders are the most common cause of suicide attempts. In this study, sample $2(16.66 \%)$ males and 10 $(83.33 \%)$ females were found without psychiatric diagnosis and remaining 33 (37.5\%) males and 55 (62.5\%) females were suffering with psychiatric disorders. The relationship between gender and psychiatric disorders in suicide attempters showing most of the females with psychiatric illness attempted suicide (62.5\%) compared to males (37.5\%). This difference was not statistically significant. Similar observations were made by Mościcki et al (1994) ${ }^{20}$ and Srivastava et al (2004). ${ }^{17}$ Study by Ping Qin et al (2003) ${ }^{13}$ also reported psychiatric disorder was more likely to increase suicide risk in females than in male subjects. Chowdhury et al (2007), ${ }^{21}$ Chang B et al (2011) ${ }^{22}$ and Stern Theodore A et al (2015) ${ }^{23}$ also noticed similar results like the number of female suicide attempters exceeded that of the male attempters. In contrary to my study, Li et al (2002) ${ }^{24}$ reported in his several studies conducted in Asia have shown mostly attempts by persons who do not have a mental illness.

The Percentage of Psychiatric Diagnosis as well as the Comparison between this and Gender

In suicide attempters the female suicide attempters were more with Depression (29\% in female, $24.24 \%$ in male) and Schizophrenia (18.18\% in female, $12.12 \%$ in male). Male suicide attempters were more with Alcohol Dependence Syndrome $(18.18 \%$ in male, $3.63 \%$ in female). Personality disorders $(27.27 \%)$ and Anxiety Disorders (9.09\%) were equally seen in both genders. Schizoaffective disorder is observed in only females (3.06\%) with suicide attempt. This difference was not statistically significant $(p>0.05)$.

Similar findings were observed in Srivastava MK et al (2004),17 Qin et al (2000)7 and Alonso et al (2004).25 Major depression (which is approximately twice as common in females and is known to underlie more than half of all suicide attempts. Similar results were found in US study by Kung et al 
(2003), ${ }^{26}$ that females are $13-21 \%$ more likely than males to receive a psychiatric affective diagnosis.

The gender difference may be due to in my study the fact that majority of the females suffering with Psychiatric disorder are prone to stress, which may lead to suicide attempt in this region.

\section{Nature of Suicide Attempt in Relation with Gender}

$62 \%$ of total subjects were impulsively attempted suicide compared to planned only (38\%). In those, majority were males $77.14 \%$ followed by females (53.84\%). This difference was statistically significant $(\mathrm{p}<0.05)$.

Similar observations by Meerae Lim et al (2016) ${ }^{27}$ reported that considerable proportion of suicide attempts are the result of sudden desires. A total of $48.0 \%$ of participants in his study attempted suicide impulsively. Study by Li et al (2002) 24 reported mostly impulsive acts undertaken during stressful life events. But in contrary to my study Adam KS $(1985)^{28}$ reported male suicide attempts were planned, but female attempts were impulsive.

Relationship between Termination Behaviour in the form of whether Intoxicated (with Alcohol or other Substance) or Clear

Consciousness during the time of suicide attempt was compared with gender. Out of total $9 \%$ were intoxicated and all of them i.e. $25.7 \%$ were males, lowest among females (0\%) and most of the females were with clear consciousness during the time of attempt (100\%). This difference was statistically significant $(\mathrm{p}<0.05)$.

These results were corroborated with study by Demmie et al (1972) ${ }^{29}$ that majority were alcoholics and intoxicated at the time of suicide attempt.

Contrary to my results Chatterji et al (2004),30 the National Comorbidity Survey (NCS) focusing on adolescents found no causal relationships between alcohol drinking behaviour in general and suicide attempts, but reported a significant association between alcohol-related disorders and suicide attempts.

Mourizio Pompili et al (2010) $)^{31}$ stated reason that Alcohol abuse may lead to suicidality through disinhibition, impulsiveness and impaired judgement, but it may also be used as a means to ease the distress associated with committing an act of suicide.

But Panel Monica et al (2007) ${ }^{32}$ reported that alcohol use among adolescents, particularly preteen alcohol use initiation, is an important risk factor for both suicide ideation and suicide attempts among boys and girls. Also stated increased efforts to delay and reduce early alcohol use are needed and may reduce suicide attempts.

These results in my study may be due to a greater number of males having alcohol abuse compared to females and alcohol increases the threshold for pain and fear about consequences.

\section{Relationship with Methods used for Attempt in Male and Females}

Most common mode of attempt was with Pesticide (Organophosphorus) poisoning (49\%) followed by 29\% others (prescribed drugs antidepressants, benzodiazepines, antipsychotics, antiepileptics, antipyretics; unknown poisoning). Organ phosphorus poisoning mostly used by males $51.4 \%$ compared to females $47.6 \%$. Household chemicals (kerosene, rat killer, nail polish, phenoil) mostly used by females $(1.38 \%)$ compared to males $(0 \%)$. Other methods used were burning, hanging or self-injury in a lesser percentage. These differences were not statistically significant.

Similar observations by $\mathrm{Li}$ et al (2002) 24 in suicide attempt, of which $83 \%$ had ingested pesticides.

Similarly, study by Haw et al (2015). ${ }^{33}$ This finding propounds that even within the same method of attempted suicide, in this case intentional drug overdose, males show a stronger intent to die than females. Thus, it can be inferred that irrespective of the method of self-harm, male suicide attempts tend to be more serious than female suicide attempts.

Also, similar results found by Beautrais AL et al (2002) ${ }^{34}$ that males prefer more lethal methods (e.g. hanging), while the methods favoured by females tend to be less lethal (e.g. overdose).

Easy availability of pesticides may be the reason for its common use for suicide attempt in males.

Relationship between the Method used by Subjects for Suicide Attempt, whether it is Lethal to cause Death or May Not

Lethal on the opinion of treating physician compared with gender. Most of the subjects using may or may not be lethal methods (59\%) compared to lethal methods (41\%). In this majority of males use lethal methods $(42.85 \%)$ compared to females (40\%). This difference was not statistically significant $(\mathrm{p}$ value $>0.05)$. Similar observations made by Isometsä et al (1998),14 more number of males use lethal methods to attempt suicide compared to females which may be due to their firmness towards death. Similar observations were made by Värnik A et al (2008) ${ }^{35}$ and Cibis A et al (2012). ${ }^{36}$ Many studies have sought to explain the gender gap in suicidal behaviour by addressing lethality, suggesting that females survive suicide attempts more often than males because they use less lethal means. David Sue et al (2012) ${ }^{37}$ and Updesh Kumar et al (2017) ${ }^{38}$ also reported females are more likely to use methods that are less immediately lethal compared to males.

\section{Number of attempts with Gender Distribution}

Attempts subdivided into first and repeated. Most of the subjects attempted first (75\%) compared to repeated (25\%) and this is not statistically significant ( $p$ value $>0.05$ ). First attempt by males 26 (74.28\%) and females 49 (75.38\%), repeated attempts by males $9(25.71 \%)$ and females 16 (24.62\%). Similar findings by Adam KS (1985) ${ }^{28}$ reported male suicide attempts were multiple compared to female attempts. But the difference between male and female number of attempts is minute in my study. But in contrary to my findings were partially corroborated with Changet et al (2011) suicide attempts between two and four times more frequent among females. Also, Schrijvers DL et al (2012) ${ }^{39}$ also noticed that females engage significantly more frequently in suicide attempts. It is known as the gender paradox of suicidal behaviour. 


\section{Difference between Genders in seeking help prior to Suicide Attempt}

Most of the subjects were non-help seekers (82\%) followed by psychiatric help seekers $(13 \%)$. On comparison of values of general practitioner's help seekers (5\%), there is minute variation in gender, even though this is not statistically significant ( $\mathrm{p}$ value $>0.05$ ).

In contrary to my study by Turner (1980) ${ }^{40}$ and Ahmedani et al (2015),41 although they may not call prevention centres, people considering suicide usually do seek help. In my study, the non-help seeking might be due to lack of knowledge about psychiatric help, stigma regarding mental disorders or due to a greater number of attempts were impulsive acts.

\section{CONCLUSION}

Psychiatric disorders were found in $88 \%$ of suicide attempters. Most of the females with psychiatric disorder attempted suicide compared to males. Depressive disorders, schizophrenia and schizoaffective disorders are more in female gender attempters and alcohol dependence syndrome in male attempters. Anxiety and personality disorders are equally distributed among both genders. Impulsive attempts were significantly more common in males. Significantly more males were intoxicated with alcohol during the attempt. Pesticides and prescribed medicines are the common method of attempt, but household chemicals are used mostly by females. Most of the males used lethal methods compared to female attempters. The number of first and repeated attempts, difference is minute with gender. Non-help seekers were more prior to attempt with minute gender deference.

\section{Limitations}

1. The study was done on sample taken from the hospitalbased population. It may not be representative of persons who attempted suicide in the general population.

2. It was not a longitudinal follow-up study.

3. Transgenders were not included.

\section{Future Directions}

1. Those patients who had psychiatric diagnosis and prior attempts should be particularly given importance and treatment.

2. Men were attempting suicide with substance dependence and under intoxication, so suicide prevention strategies in men should focus on reducing comorbidities such as substance abuse.

3. Availability of pesticides, mostly organophosphorus compounds and household chemicals can also be restricted. The easy availability of these poisons makes them the most common poisons used for self-poisoning. The family members of male psychiatric patients should be warned about OP poisoning and female patients about house-hold chemicals.

4. Further studies with bigger sample size and prospective follow-up design related to gender differences may throw light upon this aspect better.

5. Future studies on neurobiological differences and treatment outcomes should be studied in relation to males, females and transgenders.

\section{ACKNOWLEDGEMENTS}

Authors would like to thank Dr. R Sateesh Babu, MD, Prof and former Head, Department of Psychiatry, Mamata Medical College, Khammam in guiding them to carry out the study.

\section{REFERENCES}

[1] Suicide in India 2014-05-13 at way back machine. The Registrar General of India, Government of India, 2012.

[2] Vijaykumar L. Suicide and its prevention: the urgent need in India. Indian J Psychiatry 2007;49(2):81-4.

[3] Strom P, Strom R. Adolescents in the internet age: teaching and learning from them. $2^{\text {nd }}$ edn. Charlotte, NC: Information Age Publishing 2014.

[4] Maris RW, Berman AL, Maltsberger TJ, et al. The relationship of nonfatal suicide attempts to completed suicide. In: Assessment \& prediction of suicide. New York: Guilford Press 1992: p. 362-80.

[5] Gvion Y, Apter A. Suicide and suicidal behavior. Public Health Reviews 2012;34(2):1-20. Epub ahead of print.

[6] Zhang J, McKeown RE, Hussey JR, et al. Gender differences in risk factors for attempted suicide among young adults: findings from the Third National Health and Nutrition Examination Survey. Ann Epidemiol 2005;15(2):167-74.

[7] Qin P, Agerbo E, Westergård-Nielsen N, et al. Gender differences in risk factors for suicide in Denmark. Br J Psychiatry 2000;177:546-50.

[8] Hawton K. Sex and suicide. Gender differences in suicidal behaviour. Br J Psychiatry 2000;177:484-5.

[9] Haw C, Hawton K, Houston K, et al. Correlates of relative lethality and suicidal intent among deliberate self-harm patients. Suicide Life Threat Behav 2003;33(4):353-64.

[10] Nordentoft M, Branner J. Gender differences in suicidal intent and choice of method among suicide attempters. Crisis 2008;29(4):209-12.

[11] Pompili M, Masocco M, Vichi M, et al. Suicide among Italian adolescents: 1970-2002. Eur Child Adolesc Psychiatry 2009;18(9):525-33.

[12] Canetto SS. Gender and suicidal behavior: theories and evidence. In: Maris RW, Silverman MM, Canetto SS, eds. Review of Suicidology. New York: Guilford Press 1997: p. 138-67.

[13] Qin P, Agerbo E, Mortensen PB. Suicide risk in relation to socioeconomic, demographic, psychiatric, and familial factors: a national register-based study of all suicides in Denmark, 1981-1997. American Journal of Psychiatry 2003;160(4):765-72.

[14] Isometsä ET, Lönnqvist JK. Suicide attempts preceding completed suicide. Br J Psychiatry 1998;173:531-5.

[15] Kumar SCT, Mohan R, Ranjith G, et al. Gender differences in medically serious suicide attempts: a study from South India. Psychiatry Res 2006;144(1):79-86.

[16] Katsching H, Sint P, Robetin FG. "Suicide and Para suicide: identification of high and low risk groups" by Chester Analysis with a 5 year follow-up. 1980: p. 154 $-66$. 
[17] Srivastava MK, Sahoo R, Ghotekar LH, et al. Risk factors associated with attempted suicide: a case control study. Indian Journal of Psychiatry 2004;46(1):33-8.

[18] Sheehan DV, Lecrubier Y, Sheehan KH, et al. The MiniInternational Neuropsychiatric Interview (M.I.N.I.): the development and validation of a structured diagnostic psychiatric interview for DSM-IV and ICD10. J Clin Psychiatry 1998;59(Suppl 20):22-33; quiz 34-57.

[19] ICD-10 Classifications of Mental and Behavioral Disorder: Clinical Descriptions and Disgnostic Guidelines. Geneva. World Health Organization, 1992.

[20] Mościcki EK. Gender differences in completed and attempted suicides. Ann Epidemiol Review 1994;4(2):152-8.

[21] Chowdhury AN, Banerjee S, Brahma A, et al. Pesticide poisoning in non-fatal deliberate self-harm: a public health issue: Study from Sundarban delta, India. Indian Journal of Psychiatry 2007;49(4):262-6.

[22] Chang B, Gitlin D, Patel R. The depressed patient and suicidal patient in the emergency department: evidence-based management and treatment strategies. Emergency Medicine Practice 2011;13(9):1-23; quiz 23-4.

[23] Stern TA, Fava M, Wilens TE, et al. Massachusetts general hospital comprehensive clinical psychiatry. $2^{\text {nd }}$ edn. London: Elsevier Health Sciences 2015: p. 589. ISBN 9780323328999.

[24] Li XY, Xu YC, Wang YP, et al. Characteristics of serious suicide attempts treated in a general hospitals. Chinese Mental Health Journal 2002;16(10):681-4.

[25] Alonso J, Angermeyer MC, Bernert S, et al. Prevalence of mental disorders in Europe: results from the European Study of The Epidemiology of Mental Disorders (ESEMeD) project. Acta Psychiatr Scand Suppl 2004:(420):21-7.

[26] Kung HC, Pearson JL, Liu X. Risk factors for male and female suicide decedents ages 15-64 in the United States. Results from the 1993 National Mortality Followback Survey. Soc Psychiatry Psychiatr Epidemiol 2003;38(8):419-26.

[27] Lim M, Lee S, Park JI. Differences between impulsive and non-impulsive suicide attempts among individuals treated in emergency rooms of South Korea. Psychiatry Investigation Journal 2016;13(4):389-96.

[28] Adam KS. Attempted suicide. Psychiatric Clinics of North America 1985;8(2):183-201.
[29] Mayfield DG, Montgomery D. Alcoholism, alcohol intoxication and suicide attempts. Arch Gen Psychiatry 1972;27(3):349-53.

[30] Chatterji P, Dave D, Kaestner R, et al. Alcohol abuse and suicide attempts among youth. Econ Hum Biol 2004;2(2):159-80.

[31] Pompili M, Serafini G, Innamorati M, et al. Suicidal behavior and alcohol abuse. Int J Environ Res Public Health 2010;7(4):1392-431.

[32] Swahn MH, Bossarte RM. Gender, early alcohol use and suicide ideation and attempts: findings from the 2005 youth risk behavior survey. Journal of Adolescent Health 2007;41(2):175-81.

[33] Haw C, Casey D, Holmes J, et al. Suicidal intent and method of self-harm: a large-scale study of self-harm patients presenting to a general hospital. Suicide Life Threat Behav 2015;45(6):732-46.

[34] Beautrais AL. Gender issues in youth suicidal behavior. Emergency Medicine (Fremantle) 2002;14(1):35-42.

[35] Värnik A, Kõlves K, Feltz-Cornelis CM, et al. Suicide methods in Europe: a gender-specific analysis of countries participating in the "European Alliance Against Depression". J Epidemiol Community Health 2008;62(6):545-51.

[36] Cibis A, Mergl R, Bramesfeld A, et al. Preference of lethal methods is not the only cause for higher suicide rates in males. J Affect Disord 2012;136(1-2):9-16.

[37] Sue D, Sue DW, Sue S, et al. Understanding abnormal behavior. (10 ${ }^{\text {th }}$ edn, [student edn.] ed). Belmont, CA: Wadsworth/Cengage Learning (2012-01-01). p. 255. ISBN 978-1-111-83459-3.

[38] Kumar U, Mandal MK. Suicidal behaviour: assessment of people-at-risk. Sage Publications India Pvt Ltd., New Delhi. Industrial Psychiatry Journal 2010;19(2):139. Retrieved March 4, 2017. ISBN 8132104994.

[39] Schrijvers DL, Bollen J, Sabbe BG. The gender paradox in suicidal behaviour and its impact on the suicidal process. J Affect Disord 2012;138(1-2):19-26.

[40] Turner RJ. The use of health services prior to non-fatal deliberate self-harm. In: Farmer RDT, Hirsch SR, eds. The suicide syndrome. London: Croon Helm 1980: p. 173-86.

[41] Ahmedani BK, Stewart C, Simon GE, et al. Racial/Ethnic differences in health care visits made before suicide attempt across the United States. Medical Care 2015;53(5):430-5. 